\title{
0 CUSTO QUE ENVOLVE A RETIRADA DE MÚLTIPLOS ÓRGÃOS
}

\author{
Cícera Izabel C. de Oliveira Guerra, Olímpio J. Nogueira V. Bittar*,
} Moacir R. de Siqueira Júnior, Fumio Araki

Trabalho realizado no Instituto Dante Pazzanese de Cardiologia, São Paulo, SP

RESUMO - 0 processo que envolve a doação e retirada de órgãos é complexo e tem um custo elevado para os hospitais que 0 realizam. Neste artigo é estimado 0 custo médio total envolvido nesse processo, comparando-o com a remuneração paga pelo Sistema Único de Saúde.

OBjETIVO. Levantar os gastos com captação, manutenção do doador e retirada de órgãos para transplante.

Métodos, É um estudo retrospectivo, baseado no levantamento dos prontuários de 32 doadores admitidos na Organização de Procura de Órgãos do Instituto D ante Pazzanese de Cardiologia, São Paulo, no período de janeiro a dezembro de 1999. Os gastos levantados foram em relação aos seguinte itens: recursos humanos, material de consumo, utilidade pública, exames complementares, depreciação de equipamentos, material permanente e transporte.

Resultados, 0 estudo realizado encontrou 0 custo médio de $\mathrm{R} \$ 2.883,34$ para o processo de doação, captação e retirada de órgãos, desde a avaliação até a entrega do corpo a família. 0 valor pago pelo SUS é de $\mathbf{R} \$ 1.853,71$. Este custo cobre $65 \%$ do custo médio real.

Conclusã̄o 0 artigo demonstra a importância da realização de estudos de custos, de procedimentos, com o objetivo de orientar a definição/atualização das tabelas de remuneração de serviços.

Unitermos: Doadores de órgãos. Transplante. Custo dos procedimentos.

\section{INTRODUÇÃO}

A história dos transplantes é marcada por frustraçōes e conquistas. Várias tentativas em animais foram feitas até que se conseguisse realizar o procedimento no ser humano.

No início do século 20, por volta de 1902, foi realizado o primeiro transplante renal autólogo em um cão. Em 1933, realizou-se na Ucrânia o primeiro transplante renal em humanos, infelizmente sem sucesso.

O êxito no campo dos transplantes começou a surgir por volta de 1946, quando um enxerto renal funcionou por três dias. Observou-se que, embora as técnicas cirúrgicas tivessem evoluído, surgiu um novo fantasma: a rejeição, levando

*Correspondência :

Rua Dr. Dante Pazzanese n.500 - Ibirapuera São Paulo - SP - Cep: 04012-909 os pesquisadores a fazerem vários estudos e tentativas com o objetivo de contornar e debelar a rejeição.

Na década de 60, a rejeição começou a ser controlada, atingindo seu apogeu na década de 80 com uma droga imunossupressora denominada ciclosporinal.

Até 1959, a morte era atribuída à parada total e irreversível do coração, no entanto um importante conceito surgiu na ciência que transferiu do coração para o encéfalo a fonte de vida. Com este novo conceito, em 1967, o Dr. Chistian Barnard realizou na África do Sul o primeiro transplante cardíaco. No ano seguinte, o Dr. Euriclides J. Zerbini realizou o primeiro transplante cardíaco no Brasil, tendo o receptor sobrevivido 28 dias.

Vencidas as dificuldades técnicas e controlada a rejeição, surgiram novos problemas tais como a falta de doadores e legislações que estabelecessem normas e rotinas para o diagnostico de morte encefálica, assim como critérios para realização dos transplantes.

No início da década de 90 foi sancionada a Lei $n^{0} 8.489$, de 19/1 I/92, regulamentando os transplantes no Brasil. Esta lei não estabelecia os critérios para diagnóstico de morte encefálica, cadastro técnico de equipes, hospitais transplantadores e pacientes receptores, fazendo com que inúmeras discussões e pesquisas fossem realizadas envolvendo o tema².

Em 1997, foi publicada a Lei 9.434, regulamentada pelo Decreto Federal $n^{\circ}$ 2.268/97, que dispõe sobre a remoção de órgãos, tecidos e partes do corpo humano para fins de transplante e tratamento, revogando a lei 8.489/923.

Obedecendo a Lei 9.434/97, as secretarias estaduais de saúde submeteram-se a um processo de reestruturação, com o intuito de viabilizar o maior número possível de doadores. 
Em São Paulo, a Resolução da Secretaria de Saúde n¹03 /97, dispõe sobre a estrutura organizacional e operacional do Sistema Estadual de Transplante, transferindo às Organizações de Procura de Órgãos (OPO) a responsabilidade de avaliar, confirmar - diagnóstico de morte encefálica, abordar a família quanto a doação, fazer a captação e manutenção do doador, bem como a retirada, acondicionamento dos órgãos até o implante e entrega do corpo à família. Surgiu então a necessidade de toda uma infraestrutura com capacidade para funcionar 24 horas 4 .

Esta infra-estrutura requer um custo que é repassado para a OPO através do Sistema Único de Saúde (SUS) conforme a Portaria n $3.410 / 98^{5}$.

O Instituto Dante Pazzanese de Cardiologia, instituição governamental da Secretaria da Saúde do Estado de São Paulo, é uma OPO desde outubro de 1997.

Com base nessa vivência, decidiu-se fazer um levantamento do custo de todos os procedimentos realizados, materiais de consumo utilizados, custo da depreciação dos equipamentos e material permanente de metade de sua vida útil, profissionais envolvidos e serviços de utilidade pública utilizados durante o processo, que vai desde a notificação até a entrega do corpo à família.

Segundo Bittar ${ }^{8}$, embora a montagem da contabilidade de custos em hospitais não seja um trabalho complicado, a técnica é muito pouco utilizada, logo as discussões entre preço a ser pago pelos procedimentos e custos dos mesmos estão desvinculados de uma base sólida, levando a prejuízos para a Instituição. A preocupação com custos de transplantes tem aumentado, como pode ser visto nos artigos de Stavemk ${ }^{6}$ e Hu 7 .

\section{Métodos}

Campo de realização do estudo

Este estudo é retrospectivo, realizado no Instituto Dante Pazzanese de Cardiologia-IDPC, na unidade de transplante com capacidade para admitir três doadores, 24 horas por dia.

O IDPC é um hospital público governamental com 245 leitos e camas, especializado no atendimento de pacientes com doenças cardiovasculares, transplantes de rim e coração.

População

Doadores de múltiplos órgãos admitidos no IDPC de janeiro a dezembro de 1999.

\section{Amostra}

32 doadores de múltiplos órgãos.

Coleta de dados

Levantou-se:

- a média de horas despendidas com a manutenção do doador desde a notificação até a entrega do corpo à família;

- a quantidade média de material de consumo utilizado;

- a depreciação do material permanente e equipamentos;

- Os profissionais envolvidos na manutenção, captação e realização de exames diagnósticos complementares, carga horária e salários;

- os serviços de utilidade pública (energia elétrica, água e telefonia)

- gás medicinal, ambulância e UTI móvel (serviço terceirizado).

Cálculos para obtenção da depreciação dos equipamentos e material permanente.

Vd $=$ Valor Depreciado

Ve $=$ Valor Equipamento

Tx = Taxa de Depreciação

$V d=\operatorname{Ve} x T x$
$\mathrm{Cp}=$ Custo por Procedimento

$\mathrm{Hu}=$ Horas de Uso

$C p=((V d / 365) / 24) * H v$

\section{Cálculo utilizado para obtenção do custo com os serviços de utilidade pública (água e energia elétrica e telefonia).}

At $=$ área total do complexo hospitalar = 29.347,20 $\mathrm{m}^{2}$

As = área de cada setor

As (\%) da área ocupada por setor:

$$
\text { As }(\%)=\frac{\text { As }}{\text { At }}
$$

O Custo é igual a área em $\mathrm{m}^{2}$, multiplicado pelo gasto médio mensal.

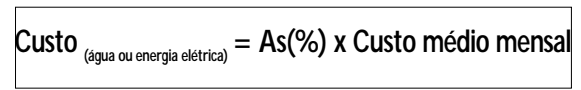

Telefonia

Is $=$ Impulsos registrados no setor

$\mathrm{Ci}=$ Custo unitário por impulso

$\mathrm{Cs}_{\mathrm{s}}=$ Custo do setor

Custo do setor:

\section{Cs $=\mathrm{Ci} \times \mathrm{Is}$}

Oxigênio líquido

Para o cálculo do custo de consumo de oxigênio líquido foram considerados os seguintes parâmetros:

Vazão média $=15$ litros por minuto Tempo de utilização $=T$ (minutos) Custo unitário de compra em $\mathrm{m}^{3}$ de oxigênio líquido $=R \$ 2,29$

Cálculo do custo:

$$
C=\frac{15 \times T}{100} \times R \$ 2,29
$$




\section{Salários}

O salário-base dos profissionais envolvidos e o custo-hora de cada um foi calculado da seguinte maneira: saláriobase / carga horária mensal = saláriohora. O valor da hora trabalhada é multiplicado pelo número de horas despendidas com o doador, obtendose o custo por procedimento.

\section{Resultados e Discussão}

Os resultados obtidos evidenciaram que $68,7 \%$ (22) dos doadores eram do sexo masculino e $31,2 \%$ (10) feminino, com idade média de 36,5 anos, sendo que a idade mínima foi de 12 anos e a máxima de 61 anos. As principais causas da morte foram traumatismo craniencefálico (TCE) I4 (43,7\%), acidente vascular cerebral (AVC) nove $(28,1 \%)$, ferimento por arma de fogo (FAF) oito (25\%), outros, um $(3,1 \%)$.

O tempo médio gasto no processo, que vai desde a notificação do doador até a entrega do corpo à família, foi de 37,5 (trinta e sete horas e trinta minutos).

O custo médio do material descartável e medicamentos utilizados no doador de múltiplos órgãos, desde a avaliação até a entrega do corpo à família, é demonstrado na Tabela I.

Os medicamentos referidos na Tabela I são: revivan, cloreto de potássio, cloridrato de dobutamina, desmopressina, sulfato de magnésio, cafazolina (antibiótico profilático), glicose a 10\%, soro glicosado a 5\%, soro fisiológico 0,9\%, solução de ringer lactato e solução de gelatina.

Os materiais descartáveis são: aventais, agulhas $(30 / 7,25 / 6,40 / 12)$, cateteres periféricos (jelcos, escalpes), centrais (intra- cath), coletor de urina (sistema aberto e fechado), compressas, cortoplast, gazes, dial flow, eletrodos, equipos

\section{Tabela 1 - Gasto médio com medicamentos e material descartável utilizado no doador de múltiplos órgãos}

\begin{tabular}{lcccc}
\hline Insumos & Centro cirúrgico & Terapia intensiva & Hemodinâmica & Total \\
Medicamentos* & 63,89 & 198,74 & 69,23 & 331,86 \\
Mat. descartável & 575,00 & 180,14 & 573,60 & 1328,74 \\
TOTAL & $\mathbf{6 3 8 , 8 9}$ & $\mathbf{3 7 8 , 8 8}$ & $\mathbf{6 4 2 , 8 3}$ & $\mathbf{1 . 6 6 0 , 6 0}$ \\
\hline
\end{tabular}

* Inclui soluções e soros.

Tabela 2 - Material permanente utilizado no doador durante a permanência na hemodinâmia, UTI, centro cirúrgico, segundo quantidade utilizada, preço, taxa de depreciação, custo/hora de utilização em reais

\begin{tabular}{|c|c|c|c|c|c|}
\hline $\begin{array}{l}\text { Material qua } \\
\text { permanente }\end{array}$ & |uantidade & $\begin{array}{c}\text { Preço/novo } \\
\text { R\$ }\end{array}$ & $\begin{array}{c}\text { Taxa } \\
\text { Depreciação } \\
\% *\end{array}$ & $\begin{array}{c}\text { Tempo de } \\
\text { utilização } \\
\text { (horas) }\end{array}$ & $\begin{array}{l}\text { Custo da } \\
\text { utilização } \\
\text { p/ Procedim. }\end{array}$ \\
\hline Cama & | & $1.549,00$ & 10 & 7 & 0,62 \\
\hline Maca & | & $1.474,00$ & 10 & 0,5 & 0,04 \\
\hline Suporte/soro & 3 & 347,00 & 10 & 7 & 0,42 \\
\hline Mesa cirúrgica & | & $17.218,00$ & 10 & 7 & 6,88 \\
\hline Mesas auxiliares & 3 & 787,00 & 10 & 7 & 0,94 \\
\hline Focos/teto & 2 & $5.445,00$ & 10 & 7 & 4,35 \\
\hline Focos/auxiliar & 2 & $4.768,00$ & 10 & 7 & 3,81 \\
\hline Carro de anestesia & | & $100.000,00$ & 10 & | & $5,7 \mid$ \\
\hline Serra elétrica & | & $40.000,00$ & 20 & 7 & 15,98 \\
\hline Caixa de instrumental & ntal 3 & $14.000,00$ & 10 & 7 & 16,78 \\
\hline Bisturi elétrico & I & $7.800,00$ & 10 & 7 & 3,12 \\
\hline TOTAL & & & & & 58,65 \\
\hline
\end{tabular}

* ver referência 9

de soro (macrogotas, microgotas, bomba de infusão life med, pressão venosa central, sangue e derivados), esparadrapo, filtro para sistema ventilatório, gorro, lâminas de bisturi (n. Il, 22), luvas descartáveis estéreis e de procedimentos, máscaras cirúrgicas, manta térmica, micropore, lâmina de barbear, seringas $(\mathrm{l}, 5,10$ e $20 \mathrm{ml})$, sondas de aspiração ( $\mathrm{n}^{\circ}$ 10 el2), torneirinhas, fios cirúrgicos, cateteres angiográficos (simons, judkins direita e esquerda), perfusor set, tubos para coleta de sangue, touca, propés, campos cirúrgicos e saco para cadáver.

O material permanente utilizado no doador, durante sua permanência nos setores de estudo hemodinâmico, terapia intensiva e centro cirúrgico é demonstrado na Tabela 2.

Conforme os dados da Tabela 2, um número significativo de material permanente é utilizado, demostrando a complexidade do cuidar do doador. O custo de utilização desse material é de $R \$ 58,65$, relativamente baixo que, ao somarmos com os outros gastos, chega-se a um montante significativo.

A admissão do doador no setor de estudos hemodinâmicos se justifica em razão da necessidade da confirmação da morte encefálica que é feito através da angiografia cerebral. 0 
Tabela 3 - Equipamentos e serviço de transporte necessários à captação e manutenção do doador na hemodinâmica, UTI e centro cirúrgico, segundo quantidade, preço, durabilidade, taxa de depreciação, tempo de utilização e custo/hora em reais

\begin{tabular}{|c|c|c|c|c|c|}
\hline Equipamentos & Quantidade & $\begin{array}{c}\text { Preço } \\
\text { R\$ }\end{array}$ & $\begin{array}{c}\text { Taxa de } \\
\text { depreciação } \\
\%\end{array}$ & $\begin{array}{c}\text { Tempo de } \\
\text { utilização } \\
\text { (horas) }\end{array}$ & Custo/horas \\
\hline $\begin{array}{l}\text { Aparelho de } \\
\text { Eletrocardiograma }\end{array}$ & | & $2.046,90$ & 10 & 0,5 & 0,06 \\
\hline Monitor cardíaco & | & $6.790,00$ & 10 & 7 & 2,71 \\
\hline Ventilador portátil & 1 & $15.08 \mid, 90$ & 10 & 2 & 1,72 \\
\hline Ventilador volume 6400 & | & $39.060,56$ & 10 & 7 & $|5,6|$ \\
\hline Oxímetro de pulso & 1 & $2.200,00$ & 10 & 7 & 0,88 \\
\hline $\begin{array}{l}\text { Aparelho de } \\
\text { Cinecoronariografia }\end{array}$ & | & $1.932 .000,00$ & 10 & | & 110,27 \\
\hline $\begin{array}{l}\text { Ambulância** } \\
\text { TOTAL }\end{array}$ & | & $50.000,00$ & 25 & 6 & $\begin{array}{c}17,12 \\
148,37\end{array}$ \\
\hline
\end{tabular}

* ambulância utilizada para o transporte da enfermeira na abordagem

\begin{tabular}{|c|c|c|c|c|c|c|c|}
\hline Sub-áreas & $\begin{array}{c}\text { Tempo } \\
\text { permanência } \\
\text { (h) }\end{array}$ & $\begin{array}{l}\text { Água } \\
\text { (R\$) }\end{array}$ & $\begin{array}{c}\text { Energia } \\
\text { Elétrica } \\
\text { (R\$) }\end{array}$ & $\begin{array}{c}\text { Gases (R\$) } \\
\text { (Oxigênio } \\
\text { liquído) }\end{array}$ & $\begin{array}{l}\text { Limpeza } \\
\text { (R\$) }\end{array}$ & $\begin{array}{c}\text { Telefonia } \\
\text { (R\$) }\end{array}$ & $\begin{array}{l}\text { Total por } \\
\text { Sub-áreas }\end{array}$ \\
\hline Centro-cirúrgico & 7,0 & 6.65 & 0,94 & 2.06 & 6,14 & 0,03 & 15,82 \\
\hline Hemodinâmica & 1,5 & 1,42 & 0,20 & 3,09 & $|, 3|$ & 0,07 & 6,09 \\
\hline UTI & 8,0 & 0,73 & 0,10 & 16,49 & 0,68 & 0,08 & 18,08 \\
\hline TOTAL & & 8,80 & 1,24 & 21,64 & 8,13 & 0,18 & 39,99 \\
\hline
\end{tabular}

cateterismo cardíaco é necessário quando o doador tem idade igual ou maior a 40 anos.

Ao ser constatada a morte encefálica, faz-se a transferência do doador para UTI, para dar continuidade a manutenção do doador.

Para manter os órgãos funcionando, há necessidade da utilização de equipamentos que auxiliem e monitorem.

Os equipamentos utilizados no monitoramento dos doadores são demonstrados na Tabela 3.

A utilização destes equipamentos é justificada pela importância que se deve dar à manutenção adequada dos órgãos até a retirada cirúrgica, evitando-se que os órgãos sejam lesados antes do implante. Conforme demostrado na Tabela 3, investimento e manutenção são necessários, gerando um custo de $R \$ 148,37$ (cento e quarenta e oito reais e trinta e sete centavos) por doador.

O meio de transporte utilizado pela enfermeira quando sai para avaliar e abordar a família do doador é uma ambulância, que conforme mostra a Tabela 3, requer um custo na preservação e manutenção.

A importância média gasta por doador com combustível em ambulância própria do hospital, no período de janeiro a dezembro de 1999 foi de $\mathrm{R} \$$ I.014,13, obtendo-se um custo médio por saída de $\mathrm{R} \$ 24,73$, percorrido uma média $2.337 \mathrm{~km}$ por mês.

O custo da UTI móvel (serviço terceirizado) por cada doador é de $\mathrm{R} \$$ 390,00, distância máxima permitida $150 \mathrm{~km}$.

O doador, ao ser admitido, é submetido a uma série de procedimentos, atendendo a Lei.n ${ }^{\circ}$ 9.434/97.

A sua permanência na instituição envolve gastos com água, energia elétrica, telefonia, limpeza e gases medicinais. Este custo está demonstrado na Tabela 4.

Do total de 37h30, utilizadas desde a notificação até a entrega do corpo à família, são distribuídas entre os setores descritos na Tabela 4. 
Conforme evidenciam os dados da Tabela 4, o custo com os serviços de utilidade pública é de $\mathrm{R} \$ 39,99$.

O doador é mantido como um paciente grave, que requer cuidados e mãode-obra especializada para a sua adequada manutenção, realizado por uma equipe multiprofissional, demostrado na Tabela 5.

Conforme mostra a Tabela 5, uma equipe multiprofissional é necessária para cuidar do doador em função da complexidade que envolve a avaliação, manutenção do doador. $\mathrm{O}$ custo com a mão-de-obras desses profissionais é de $R \$ 436.37$.

A realização dos exames complementares de diagnóstico é necessário para descartar a possibilidade de lesões nos órgãos, doenças infecto-contagiosas e infecções sistêmicas que serão realizados sob a responsabilidade OPO, cujo custo é demonstrado na Tabela 6.

Quando os resultados dos exames são concluídos e realizadas as correções, comunica-se com a Central de Transplante- CTX, via fax.

A CTX, ao ser comunicada, identifica os potenciais receptores e suas respectivas equipes transplantadoras.

A enfermeira da OPO, ao tomar conhecimento das equipes que participarão da retirada, programa a retirada cirúrgica dos órgãos.

Após a retirada, o cadáver é recomposto e encaminhado para o Instituto Médico Legal ou Serviço de Verificação de Óbito.

Conforme demonstrado na Tabela 6, o custo dos exames complementares de diagnósticos é de $R \$ 110,40$, que já estão incluídos na diária de UTI, repassados pelo Sistema Único de Saúde no valor de $R \$ 2|3,7|$, no entanto,

\section{Tabela 5 - Tempo dedicado pelos profissionais ao doador de múltiplos órgãos, segundo tempo dispensado e custo*}

\begin{tabular}{lccc}
\hline Profissional & Tempo & Valor/hora & Gasto total R\$ \\
Médico** & 4 & 13,97 & 55,88 \\
Enfermeiro & 30 & 4,93 & 147,90 \\
Auxiliar de enfermagem & 30 & 3,41 & 102,30 \\
Motorista & 6 & 2,84 & 17,04 \\
Escriturário & 37 & 2,37 & 87,69 \\
Biologista & 4 & 6,39 & 25,56
\end{tabular}

TOTAL

436,37

*Salários pagos pela Secretaria de Estado da Saúde São Paulo *** Médicos intensivista, hemodinamicista, neurologista e cirurgião.

\section{Tabela 6 - Processamento dos exames complementares de diagnóstico segundo custo e quantidade}

\begin{tabular}{lcc}
\hline Exame & Q uantidade & Custo R\$** \\
Bioquímica completa & 2 & 10,08 \\
Hemograma completo & $\mid$ & 1,30 \\
Coagulograma & $\mid$ & 5,57 \\
Gasometria arterial & 3 & 10,95 \\
Sorologia* & $\mid$ & 96,73
\end{tabular}

TOTAL

124,63

* HIV, HTL e v, e v , toxoplasmose IGM, IGG, citomegalovirus IgG, IgM, hepatite B e C, VDRL e chagas.

*** Custo calculado pelo hospital da OPO.

\section{Tabela 7 - Remuneração SUS para doador de múltiplos órgãos}

\section{Captação}

Localização do doador*

Avaliação de morte encefálica

Diária UTI

Tipagem sangüínea

Angiografia Cerebral

Taxa sala cirúrgica

Retirada de coração

Retirada de rim

Sorologia

Coordenador de sala cirúrgica

Líquido de preservação ***

Manutenção hemodinâmica

TOTAL

\section{Remuneração}

SUS R\$

70,00

170,00

$213,7 \mid$

15,00

350,00

250,00

195,00

195,00

75,00

50,00

70,00

200,00

* Acima de 2 anos ** Rim e coração 


\section{Tabela 8 - Custo médio que envolve a captação e retirada de órgãos}

Itens/gasto
Material descartável e medicamentos (tab. I)
Material permanente depreciação (tab.2)
Equipamentos e transporte, depreciação (tab. 3)
Utilidade pública (tab.4)
Recursos Humanos (tab.5)
Exames complementares (tab.6)
Ambulância(UTI móvel)
Gasolina

TOTAL
Total
$1.660,60$
58,65
148,37
39,99
436,37
124,63
390,00
24,73

sabe-se que o custo da diária da UTI, só de material de consumo e medicamentos é de $R \$ 378,88$, sem levar em consideração os serviços de utilidade pública, mão-de-obra especializada e depreciação dos equipamentos e material permanente. Se somarmos ao custo dos exames de diagnóstico, a OPO ficará com um déficit em suas contas no valor aproximado de $\mathrm{R} \$ 178,84$.

A cobertura dos gastos com a retirada dos órgãos é realizada pelo Sistema Único de Saúde, através da Portaria GM/MS n 92 de 23/I/201, cujos valores encontram-se na Tabela 7.

gasto real que a Instituição realiza com o processo de captação e retirada de órgão está descrito na Tabela 8.

O reembolso realizado pelo Sistema Único de Saúde cobre 64,29\% do gasto real conforme demonstra a Tabela 8. Os procedimentos cobertos pelo SUS estão aquém dos procedimentos realizados de fato, visto que não foram contemplados pela Portaria GM/MS no 92 de 23 /01/ 2001 , os exames complementares de diagnóstico, tais como eletrocardiograma, raios $X$, urina I, bioquímica, hemograma, coagulograma e várias gasometrias arteriais. Somente a sorologia e tipagem foram inclusos. No entanto, os outros exames são de importância fundamental na avaliação dos órgãos, sendo que sem os mesmos torna-se difícil a avaliação do seu funcionamento. O valor total pago pelo SUS é de $R \$ 1.853,7 \mid$ e o gasto real é de $R \$$ $2.883,34$.

\section{Conclusões}

O custo total do processo de doação de órgãos, desde a avaliação até a entrega do corpo à família, é de $R \$ 2.883,34$, levando-se em consideração os materiais descartáveis, medicamentos, mão-deobra especializada, taxa de água, energia elétrica, telefone, oxigênio, limpeza, transporte e depreciação de materiais permanente e equipamentos/veículos.

Não foram incluídos os custos com investimentos em instalações prediais, arcomprimido, vácuo e treinamento de pessoal.

O valor pago pela tabela SUS, desde a avaliação até a entrega do corpo à família, é de $R \$ 1.853,71$, resultando numa diferença negativa de $R \$ 1.029,63$, por doador, valor este que, teoricamente, está coberto nos hospitais públicos pelo orçamento próprio de cada unidade.

É importante que seja realizado controle de custos para todos os procedimentos que envolvam as fontes de re- ceita; estudos sobre a margem excedente, ou seja, o lucro para a recuperação do capital empregado, devem também ser considerados.

\section{SUMmarY}

\section{Cost that involves the retriet of MULTIPLE ORGANS}

The process of organ donation and retreat is complex and involves a high cost for hospitals that do it.

PURPOSE. to survey the expenses with the process of donation and retreat of organs.

METHODS, retrospective study based on medical records of 32 donors, admitted in the Search Organs Organisation do Instituto Dante Pazzanese de Cardiologia, during the period from January to December of 1999.

RESULTS, the process is complex and involves a special structure as well as 24 hours of activities, making it costly. Expenses were related with the following items: human resources, permanent material, public utilities, complementary examinations, depreciation of equipment and transportation. A comparison with the values reimbursed by the Single Health System (SUS) followed.

CONCLUSION. the total cost was high than the reimbursement provided by SUS, showing the necessity of research about cost of procedures and the reinvestment margin. [Rev Assoc Med Bras 2002; 48(2): 156-62]

KEY WORDS: Organ donors. Transplantation. Costs of procedures.

\section{REFERÊNCIAS}

I. Stolf NAG, Jatene AD. História do transplante cardíaco Rev Soc Cardiol Estado de São Paulo, 1995; 5(6):609- 13.

2. BRASIL. Lei n. 8.489 de 18 de novembro de 1992. Dispõe sobre a retirada e transplante de tecidos, órgãos e partes do corpo humano, com fins terapêuticos e científicos e dá outra providencias. Código Civil Brasileiro. São Paulo, Saraiva: 991-2.

3. BRASIL. Lei n. 9434 de 4 de fevereiro de 1997. 
GuerRa CICO et al

Dispõe sobre a remoção de órgãos, tecidos e partes do corpo para fins de transplante e tratamento. Diário Oficial da União, Brasília, 5 de fevereiro de 1997. Seção I, 2202.

4. SÃO PAULO (ESTADO). Resolução n. 103 de I de setembro de 1977. Dispõe sobre a estrutura organizacional e operacional do Sistema Estadual de Transplante. Publicada em 5 de fevereiro de 1997. Diário Oficial do Estado, São Paulo, 5 de fevereiro del 997.
5. BRASIL, Ministério da Saúde. Portaria n. 3. 4I 0, de 5 de agosto de 1998, Diário Oficial da União I2I, de 28 de junho de 1999.

6. Stavem K, kristensen, KOF. Expected costs for small-scale organ transplantation programs. Transplantation Proceedings 1998; 30:4309-13

7. Hu, R. H., Lee, P. H., Tsai, M.K., Lee C. Y., Medical cost difference between renal transplantation, Transplantation Proceedings, 30, 3617-20, 1998
8. Bittar, O J N V, Hospital: qualidade \& produtividade, Sarvier, 1997.

9. IOB. Informações Objetivas. Imposto de Renda/ Contribuição Social. 2000; 34(3): I - 16.

Artigo recebido: 24/04/200 I

Aceito para publicação: 30/01/2002 